\title{
Incoherent Oscillations Accompanying Charge Separation in Photosynthetic Reaction Centers
}

\author{
A. G. Yakovlev ${ }^{1}$, V. A. Shuvalov ${ }^{1,2}$ \\ ${ }^{1}$ A.N. Belozersky Institute of Physico-Chemical Biology, Moscow State University, Moscow, Russia \\ ${ }^{2}$ Institute of Basic Biological Problems, Russian Academy of Sciences, Moscow, Russia \\ Email: yakov@genebee.msu.su,shuvalov@issp.serpukhov.su
}

Received May 2013

\begin{abstract}
Early events of charge separation in reaction centers (RCs) of bacterial photosynthesis are modeled by kinetic equations with time-dependent rate constants. An illustrative case of regular motion along a "slow" coordinates leading to oscillations in the kinetics is examined. Different schemes of charge separation are investigated. A good fitting of experimental kinetics of native Rba. sphaeroides RCs is achieved in the five states model $\mathrm{P}_{1} \mathrm{~B}_{\mathrm{A}} \mathrm{H}_{\mathrm{A}} \leftrightarrow \mathrm{P}_{2}{ }_{2} \mathrm{~B}_{\mathrm{A}} \mathrm{H}_{\mathrm{A}} \leftrightarrow \mathrm{I} \leftrightarrow \mathrm{P}^{+} \mathrm{B}_{\mathrm{A}}^{-} \mathrm{H}_{\mathrm{A}}$ $\leftrightarrow \mathrm{P}^{+} \mathrm{B}_{\mathrm{A}} \mathrm{H}_{\mathrm{A}}^{-}$with two excited states $\mathrm{P}_{1}^{*} \mathrm{~B}_{\mathrm{A}} \mathrm{H}_{\mathrm{A}}$ and $\mathrm{P}_{2}^{*} \mathrm{~B}_{\mathrm{A}} \mathrm{H}_{\mathrm{A}}$ and three charge separated states $\mathrm{I}^{+} \mathrm{P}^{+} \mathrm{B}_{\mathrm{A}}^{-} \mathrm{H}_{\mathrm{A}}$ and $\mathrm{P}^{+} \mathrm{B}_{\mathrm{A}} \mathrm{H}_{\mathrm{A}}^{-}$ ( $\mathrm{P}$ is a primary electron donor, bacteriochlorophyll dimer, $\mathrm{B}_{\mathrm{A}}$ and $\mathrm{H}_{\mathrm{A}}$ are an electron acceptor, monomeric bacteriochlorophyll and bacteriopheophytin in active A-branch, respectively). In the model only the first excited state is directly populated by optical excitation. The emission of the two excited states is assumed to be at 905 and $940 \mathrm{~nm}$, respectively. The intermediate state $\mathrm{I}$ is assumed to absorb at $1020 \mathrm{~nm}$ as well as the $\mathrm{P}^{+} \mathrm{B}_{\mathrm{A}}^{-} \mathrm{H}_{\mathrm{A}}$ state. The model explains the deep oscillations in the kinetics of the $\mathrm{P}_{1,2}^{*}$ stimulated emission and of the $\mathrm{B}_{\mathrm{A}}^{-}$absorption. In the simpler schemes without the I state or with only one excited state the accordance with the experiment is achieved at unreal parameter values. A possible nature of the I and $\mathrm{P}_{2}^{*} \mathrm{~B}_{\mathrm{A}} \mathrm{H}_{\mathrm{A}}$ states and a possible incoherent nature of the oscillations are discussed.
\end{abstract}

Keywords: Photosynthesis; Charge Separation; Reaction Center; Electron Transfer

\section{Introduction}

In reaction centers (RCs) of purple bacteria Rhodobacter (Rba.) sphaeroides primary charge separation consisted in electron is transferred from excited dimer of bacteriochlorophyll $\mathrm{P}^{*}$ to monomeric bacteriochlorophyll $\mathrm{B}_{\mathrm{A}}$ within $\sim 3$ psec and from $\mathrm{B}_{\mathrm{A}}^{-}$to bacteriopheophytin $\mathrm{H}_{\mathrm{A}}$ within $\sim 1$ psec at room temperature (for reviews see $[1,2])$. Then electron is transferred to primary quinone $\mathrm{Q}_{\mathrm{A}}$ within $\sim 200$ psec. At cryogenic temperatures these reactions are accelerated by 2 - 3 times. Excitation of RCs by broadband femtosecond light pulses leads to oscillations in the kinetics of $\mathrm{P}^{*}$ emission [3] and of $\mathrm{B}_{\mathrm{A}}^{-}$ absorption [4] with a frequencies at $10-400 \mathrm{~cm}^{-1}$ (peak at $130-150 \mathrm{~cm}^{-1}$ ). These oscillations are observed in various native and mutant RCs in a wide range of temperatures. According to modern ideas, a vibrational or electronic (or both) coherence is a possible explanation of the oscillatory phenomena in the kinetics of the excited and charge separated states. A periodical motion of a vibrational wavepacket [5] or a quantum beats between the levels with close energies [6] can produce the damped oscillations in the populations of the RC states. Analysis of the coherent electron transfer was performed on the base of Redfield theory in [7] and in the dispersed polaron model [8]. The oscillations in the $\mathrm{P}^{*}$ stimulated emission band were theoretically studied by an approach of single electronic transition coupled to one or two vibrational modes [9-11]. At room temperature the quantum coherence should be destroyed very quickly due to thermal motions [12]. On the other hand, the molecular dynamics calculations revealed a number of classical vibrational modes in RCs at $20-200 \mathrm{~cm}^{-1}$ [13]. These modes can reflect the nuclear motions in protein matrix as well as inside the RC pigments. A classical stochastic Langevin equation was used to calculate the oscillatory dynamics of the $\mathrm{P}^{*} \rightarrow \mathrm{P}^{+} \mathrm{B}_{\mathrm{A}}^{-}$. Reaction controlled by protein relaxation [14] in modified RCs with blocked electron transfers to $\mathrm{H}_{\mathrm{A}}$.

In the present work the incoherent charge separation dynamics of native Rba. sphaeroides RCs is modeled by the kinetic equations with time-dependent rate constants. This approach is based on the Marcus theory [15]. An aim of the work was to study a possibility of incoherent origin of the oscillatory phenomena observed at early 
times of charge separation.

\section{Model}

According to Marcus theory [15], electron or energy transfer reaction occurs at the intersection of the potential energy surfaces of the initial and final states of the system. In harmonic approximation these surfaces are paraboloids shifted one from another: $U_{\text {in }}=1 / 2 m \omega^{2} x^{2}+$ $1 / 2 M \Omega^{2} X^{2} ; U_{\text {fin }}=1 / 2 m \omega^{2}\left(x-x_{0}\right)^{2}+1 / 2 M \Omega^{2}\left(X-X_{0}\right)^{2}+$ $\Delta G$. Here $x$ and $X$ are effective coordinates of fast (thermal) and slow (relaxation) motion, respectively; $m$ and $M$ are effective masses, $\omega$ and $\Omega$ are self-frequencies, $x_{0}$ and $X_{0}$ are the potential surface displacements along the $x$ and $X$ coordinates, $\Delta G$ is the free energy change of the reaction. In the high-temperature limit, the rate constants of the forward and backward reaction can be written as follows:

$$
K_{\mathrm{f}}=K_{0} \exp \left(-E / k_{B} T\right) ; K_{\mathrm{b}}=K_{\mathrm{f}} \exp \left(G / k_{B} T\right) .
$$

Here the activation energy $E=1 / 4 \lambda(1+G / \lambda)^{2}$; the energy gap $G=\Delta G+\lambda_{1}-2 \lambda_{1} X / X_{0}$; the fast reorganization energy $\lambda=1 / 2 m x_{0}^{2}$; the slow reorganization energy $\lambda_{1}=1 / 2 M \Omega^{2} X_{0}^{2} ; k_{B}$ is the Boltzmann constant; $T$ is a temperature; $K_{0}$ is a constant. After an averaging over the fast coordinate $\mathrm{x}$ the dynamics of the energy gap $G(t)$ and of the activation energy $E(t)$ is determined by the dynamics of the slow coordinate $X(t)$. Thus, the rate constants $K_{\mathrm{f}, \mathrm{b}}$ are time-dependent in this approach. In our model we examine a simplest illustrative case of damped cosine dependence of $X$ on time. We studied the schemes of three $\left(\mathrm{P}^{*} \mathrm{~B}_{\mathrm{A}} \mathrm{H}_{\mathrm{A}} \leftrightarrow \mathrm{P}^{+} \mathrm{B}_{\mathrm{A}}^{-} \mathrm{H}_{\mathrm{A}} \leftrightarrow \mathrm{P}^{+} \mathrm{B}_{\mathrm{A}} \mathrm{H}_{\mathrm{A}}^{-}\right)$, four $\left(\mathrm{P}_{1}^{*}\right.$ $\left.\mathrm{B}_{\mathrm{A}} \mathrm{H}_{\mathrm{A}} \leftrightarrow \mathrm{P}_{2}^{*} \mathrm{~B}_{\mathrm{A}} \mathrm{H}_{\mathrm{A}} \leftrightarrow \mathrm{P}^{+} \mathrm{B}_{\mathrm{A}}^{-} \mathrm{H}_{\mathrm{A}} \leftrightarrow \mathrm{P}^{+} \mathrm{B}_{\mathrm{A}} \mathrm{H}_{\mathrm{A}}^{-}\right)$and five $\left(\mathrm{P}_{1}^{*} \mathrm{~B}_{\mathrm{A}} \mathrm{H}_{\mathrm{A}} \leftrightarrow \mathrm{P}_{2}^{*} \mathrm{~B}_{\mathrm{A}} \mathrm{H}_{\mathrm{A}} \leftrightarrow \mathrm{I} \leftrightarrow \mathrm{P}^{+} \mathrm{B}_{\mathrm{A}}^{-} \mathrm{H}_{\mathrm{A}} \leftrightarrow \mathrm{P}^{+} \mathrm{B}_{\mathrm{A}} \mathrm{H}_{\mathrm{A}}^{-}\right)$ states. The coordinates of each reaction were assumed to be independent. The incoherent dynamics of relative populations of these states was described by kinetic equations.

\section{Results and Discussion}

\subsection{The Modeled Kinetics}

The results of the modeling of the five states scheme (Figure 1) are shown in Figure 2 for native RCs of Rba. sphaeroides. The calculation parameters are as follows: temperature $T=90 \mathrm{~K}$, energy difference $G_{12}^{0}=35 \mathrm{~cm}^{-1}$, $G_{23}^{0}=85 \mathrm{~cm}^{-1}, G_{34}^{0}=-400 \mathrm{~cm}^{-1}, G_{45}^{0}=-900 \mathrm{~cm}^{-1}$; reorganization energy $\lambda_{12}=80 \mathrm{~cm}^{-1}, \lambda_{23}=100 \mathrm{~cm}^{-1}, \lambda_{34}=$ $450 \mathrm{~cm}^{-1}, \lambda_{45}=1500 \mathrm{~cm}^{-1}$; reaction rate $K_{12}^{0}=26 \mathrm{psec}^{-1}$, $K_{23}^{0}=34 \mathrm{psec}^{-1}, K_{34}^{0}=12 \mathrm{psec}^{-1}, K_{45}^{0}=40 \mathrm{psec}^{-1}$; $G_{12}(t)=50 \mathrm{~cm}^{-1} \exp (-3.5 t)(\sin (30.5 t-1.2)+\sin (25.5 t-$ 1.2)); $G_{23}(t)=60 \mathrm{~cm}^{-1} \exp (-2 t)(\sin (22.5 t-0.1)+$ $\sin (27.5 t-0.1))+20 \mathrm{~cm}^{-1} \exp (-9 t) ; G_{34}(t)=-600$ $\mathrm{cm}^{-1} \exp (-5 t)+320 \mathrm{~cm}^{-1} \exp (-0.5 t) \sin (12 t-2.4) ; G_{45}(t)$
(1)

(3)

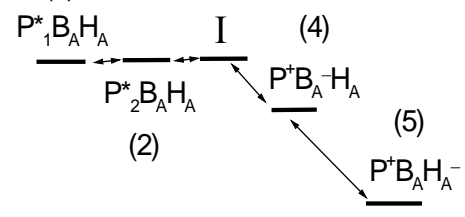

Figure 1. An illustrative scheme of the energy levels of the states at zero oscillations.

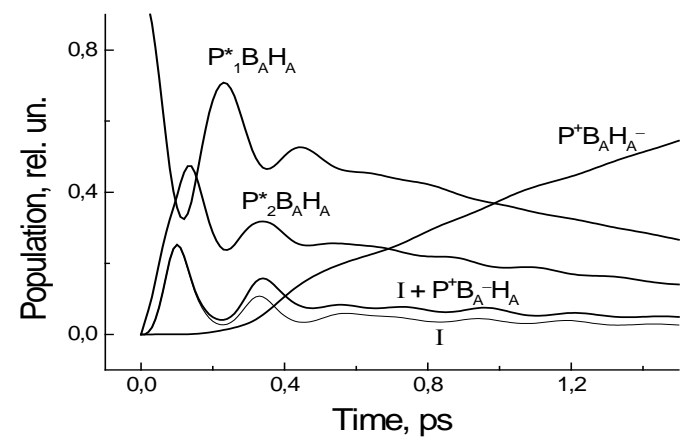

Figure 2. The modeled kinetics of the relative populations of the $\mathbf{P}_{1}^{*} \mathbf{B}_{\mathrm{A}} \mathbf{H}_{\mathrm{A}}, \mathbf{P}_{2}^{*} \mathbf{B}_{\mathrm{A}} \mathbf{H}_{\mathrm{A}}, \mathbf{I}, \mathbf{I}+\mathbf{P}^{+} \mathbf{B}_{\mathrm{A}}^{-} \mathbf{H}_{\mathrm{A}}$ and $\mathrm{P}^{+} \mathbf{B}_{\mathrm{A}} \mathbf{H}_{\mathrm{A}}^{-}$states of the native Rba. sphaeroides RCs. For details see the text.

$=0$; time $t$ is given in psec. The calculated kinetics of the states are similar with the experimental ones at $t>150$ fsec $[2-4,16]$. A decay of the $\mathrm{P}^{*}$ stimulated emission at 905 and $940 \mathrm{~nm}$ (the $\mathrm{P}_{1}^{*} \quad \mathrm{~B}_{\mathrm{A}} \mathrm{H}_{\mathrm{A}}$ and $\mathrm{P}_{2}^{*} \quad \mathrm{~B}_{\mathrm{A}} \mathrm{H}_{\mathrm{A}}$ states in the model, respectively) and a bleaching of the $\mathrm{H}_{\mathrm{A}}$ absorption band at $760 \mathrm{~nm}$ (the $\mathrm{P}^{+} \mathrm{B}_{\mathrm{A}} \mathrm{H}_{\mathrm{A}}^{-}$state) occur within $\sim 1.5$ psec in native RCs at $90 \mathrm{~K}$. These processes are accompanied by the formation of the $\mathrm{B}_{\mathrm{A}}^{-}$absorption band at $1020 \mathrm{~nm}$. The modeled sum of the I and $\mathrm{P}^{+} \mathrm{B}_{\mathrm{A}}^{-} \mathrm{H}_{\mathrm{A}}$ populations is close to the experimental kinetics of the $\mathrm{B}_{\mathrm{A}}^{-}$absorption band. This means that the I state absorb at $1020 \mathrm{~nm}$. The pronounced damped oscillations with the 220 fsec period are observed in the kinetics of the $\mathrm{P}^{*}$ stimulated emission and of the $\mathrm{B}_{\mathrm{A}}^{-}$absorption. The main contribution to the $\mathrm{B}_{\mathrm{A}}^{-}$oscillations is provided by the I state. The oscillations are completely damped within $\sim 600$ fsec. The $\mathrm{P}^{*}$ oscillations at 905 and $940 \mathrm{~nm}$ have the opposite phases, while the $\mathrm{B}_{\mathrm{A}}^{-}$absorption oscillates in phase with the $\mathrm{P}^{*}$ oscillations at $940 \mathrm{~nm}$.

\subsection{The Parameters of the Calculations}

The parameter values used in the model are in accordance with the extensive theoretical and experimental studies reviewed in $[1,2,5,14]$. According to different estimations, in Rba. sphaeroides RCs the $\mathrm{P}^{+} \mathrm{B}_{\mathrm{A}}^{-} \mathrm{H}_{\mathrm{A}}$ and $\mathrm{P}^{+} \mathrm{B}_{\mathrm{A}} \mathrm{H}_{\mathrm{A}}^{-}$energy levels are placed below the $\mathrm{P}^{*} \mathrm{~B}_{\mathrm{A}} \mathrm{H}_{\mathrm{A}}$ energy level by $300-700$ and $900-2000 \mathrm{~cm}^{-1}$, respectively. In our model the energies of the $\mathrm{P}_{1}^{*} \mathrm{~B}_{\mathrm{A}} \mathrm{H}_{\mathrm{A}}$, $\mathrm{P}^{*}{ }_{2} \mathrm{~B}_{\mathrm{A}} \mathrm{H}_{\mathrm{A}}$ and I states are different by less than $100 \mathrm{~cm}^{-1}$. 
The rates of the forward and backward reactions between these states oscillate with approximately opposite phases (Figure 3). Such correlation between the dynamics of the forward and backward reactions leads to the deep oscillations in the populations.

The molecular dynamics calculations estimate the reorganization energy of the $\mathrm{P}^{*} \mathrm{~B}_{\mathrm{A}} \rightarrow \mathrm{P}^{+} \mathrm{B}_{\mathrm{A}}{ }^{-}$and $\mathrm{P}^{*} \mathrm{H}_{\mathrm{A}} \rightarrow$ $\mathrm{P}^{+} \mathrm{H}_{\mathrm{A}}^{-}$reactions by $\sim 700 \mathrm{~cm}^{-1}$ [17] and $\sim 2000 \mathrm{~cm}^{-1}$ [18], respectively. In our model the fast reorganization energy of the $\rightarrow \mathrm{P}{ }^{+} \mathrm{B}_{\mathrm{A}}^{-} \mathrm{H}_{\mathrm{A}}\left(450 \mathrm{~cm}^{-1}\right)$ and $\mathrm{P}^{+} \mathrm{B}_{\mathrm{A}}^{-} \mathrm{H}_{\mathrm{A}} \rightarrow$ $\mathrm{P}^{+} \mathrm{B}_{\mathrm{A}} \mathrm{H}_{\mathrm{A}}^{-}\left(1500 \mathrm{~cm}^{-1}\right)$ reactions is much greater than that of the $\mathrm{P}_{1}^{*} \mathrm{~B}_{\mathrm{A}} \mathrm{H}_{\mathrm{A}} \rightarrow \mathrm{P}_{2}^{*} \mathrm{~B}_{\mathrm{A}} \mathrm{H}_{\mathrm{A}}\left(80 \mathrm{~cm}^{-1}\right)$ and $\mathrm{P}_{2}^{*} \mathrm{~B}_{\mathrm{A}} \mathrm{H}_{\mathrm{A}} \rightarrow \mathrm{I}$ $\left(100 \mathrm{~cm}^{-1}\right)$ reactions. This means the small displacement between the potential surfaces of the $\mathrm{P}_{1}^{*} \mathrm{~B}_{\mathrm{A}} \mathrm{H}_{\mathrm{A}}, \mathrm{P}_{2}^{*} \mathrm{~B}_{\mathrm{A}} \mathrm{H}_{\mathrm{A}}$ and I states.

If we assume $X / X_{0}=1$ for convenience, then the slow reorganization energy $\lambda_{1}=25,40,460,0 \mathrm{~cm}^{-1}$ for the $\mathrm{P}_{1}^{*}$ $\mathrm{B}_{\mathrm{A}} \mathrm{H}_{\mathrm{A}} \leftrightarrow \mathrm{P}_{2}^{*} \mathrm{~B}_{\mathrm{A}} \mathrm{H}_{\mathrm{A}}, \mathrm{P}_{2}^{*} \mathrm{~B}_{\mathrm{A}} \mathrm{H}_{\mathrm{A}} \leftrightarrow \mathrm{I}, \mathrm{I} \leftrightarrow \mathrm{P}^{+} \mathrm{B}_{\mathrm{A}}^{-} \mathrm{H}_{\mathrm{A}}$ and $\mathrm{P}^{+}$ $\mathrm{B}_{\mathrm{A}}^{-} \mathrm{H}_{\mathrm{A}} \leftrightarrow \mathrm{P}^{+} \mathrm{B}_{\mathrm{A}} \mathrm{H}_{\mathrm{A}}^{-}$reactions, respectively. Thus, the main part of the slow reorganization is corresponded to the $\mathrm{I} \leftrightarrow \mathrm{P}^{+} \mathrm{B}_{\mathrm{A}}^{-} \mathrm{H}_{\mathrm{A}}$ reaction, and the noticeable part of this reorganization $\left(160 \mathrm{~cm}^{-1}\right)$ is corresponded to the aperiodic motion.

In the model the values $K_{0}=26,34,12$ and $40 \mathrm{~cm}^{-1}$ were used for the $\mathrm{P}_{1}^{*} \mathrm{~B}_{\mathrm{A}} \mathrm{H}_{\mathrm{A}} \leftrightarrow \mathrm{P}^{*}{ }_{2} \mathrm{~B}_{\mathrm{A}} \mathrm{H}_{\mathrm{A}}, \mathrm{P}_{2}^{*} \mathrm{~B}_{\mathrm{A}} \mathrm{H}_{\mathrm{A}} \leftrightarrow \mathrm{I}$, I $\rightarrow \mathrm{P}^{+} \mathrm{B}_{\mathrm{A}}^{-} \mathrm{H}_{\mathrm{A}}$ and $\mathrm{P}^{+} \mathrm{B}_{\mathrm{A}}{ }^{-} \mathrm{H}_{\mathrm{A}} \rightarrow \mathrm{P}^{+} \mathrm{B}_{\mathrm{A}} \mathrm{H}_{\mathrm{A}}^{-}$reactions, respectively. In the adiabatic approximation these $K_{0}$ values are corresponded to the effective frequency $v=400-1300$ $\mathrm{cm}^{-1}$. In the nonadiabatic approximation in high temperature limit these $K_{0}$ values together with the $\lambda$ values give the electron coupling energy for the above mentioned reactions $V=74,89,77$ and $190 \mathrm{~cm}^{-1}$. The estimations of the $V$ value for the $\mathrm{P}^{*} \mathrm{~B} \leftrightarrow \mathrm{P}^{+} \mathrm{B}_{\mathrm{A}}^{-}$and $\mathrm{P}^{+} \mathrm{B}_{\mathrm{A}}^{-} \leftrightarrow \mathrm{P}^{+} \mathrm{H}_{\mathrm{A}}^{-}$ reactions are varied from $5.4 \mathrm{~cm}^{-1}$ [19] to $80 \mathrm{~cm}^{-1}$ [20] and from $15 \mathrm{~cm}^{-1}$ [21] to $480 \mathrm{~cm}^{-1}$ [20], respectively.

The qualitative agreement of our model with the experimental data can be achieved in the wide range of the parameters that indicates the stability of the model against the parameter fluctuations. The two-fold change of the

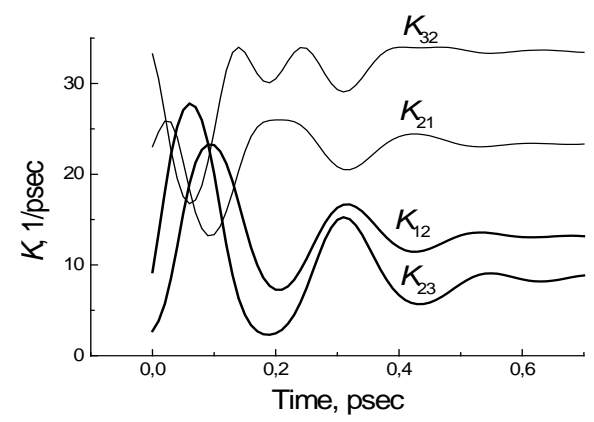

Figure 3. The calculated dependences of the forward $K_{12}$, $K_{23}$ and backward $K_{21}, K_{32}$ reaction rates $\left(1-P_{1}^{*} B_{A} H_{A}, 2-P_{2}^{*}\right.$ $\left.B_{A} H_{A}, 3-I\right)$ on time for the native Rba. sphaeroides RCs. For details see the text. energy differences, reaction rates or reorganization energies causes minor quantitative changes in the kinetics shown in Figure 2.

\subsection{Different Reaction Schemes}

Calculation shows that the simplest scheme of three states $\mathrm{P}^{*} \mathrm{~B}_{\mathrm{A}} \mathrm{H}_{\mathrm{A}} \leftrightarrow \mathrm{P}^{+} \mathrm{B}_{\mathrm{A}}^{-} \mathrm{H}_{\mathrm{A}} \leftrightarrow \mathrm{P}^{+} \mathrm{B}_{\mathrm{A}} \mathrm{H}_{\mathrm{A}}^{-}$produces more smooth oscillations than it is in experiment. In this scheme very large amplitude of the energetics changes $\sim 1000 \mathrm{~cm}^{-1}$ is necessary to obtain the oscillation amplitude comparable with experimental one. It is clear that this scheme does not explain the out-of-phase oscillations of the $\mathrm{P}^{*}$ stimulated emission at 905 and $940 \mathrm{~nm}$. These out-of-phase oscillations can be explained by the scheme of four states $\mathrm{P}_{1}^{*} \mathrm{~B}_{\mathrm{A}} \mathrm{H}_{\mathrm{A}} \leftrightarrow \mathrm{P}_{2}^{*} \mathrm{~B}_{\mathrm{A}} \mathrm{H}_{\mathrm{A}} \leftrightarrow \mathrm{P}^{+} \mathrm{B}_{\mathrm{A}}^{-} \mathrm{H}_{\mathrm{A}} \leftrightarrow$ $\mathrm{P}^{+} \mathrm{B}_{\mathrm{A}} \mathrm{H}_{\mathrm{A}}^{-}$. In this scheme the oscillatory behavior of the $\mathrm{P}^{+} \mathrm{B}_{\mathrm{A}}^{-} \mathrm{H}_{\mathrm{A}}$ state can be explained if to assume that the energetics of the $\mathrm{P}_{2}^{*} \mathrm{~B}_{\mathrm{A}} \mathrm{H}_{\mathrm{A}} \leftrightarrow \mathrm{P}^{+} \mathrm{B}_{\mathrm{A}}^{-} \mathrm{H}_{\mathrm{A}}$ reaction oscillates with unreal amplitude $\sim 1400 \mathrm{~cm}^{-1}$ or that the $\mathrm{P}^{+} \mathrm{B}_{\mathrm{A}}^{-}$ $\mathrm{H}_{\mathrm{A}}$ energy level is higher than the $\mathrm{P}_{1}^{*} \mathrm{~B}_{\mathrm{A}} \mathrm{H}_{\mathrm{A}}$ and $\mathrm{P}_{2}^{*}$ $\mathrm{B}_{\mathrm{A}} \mathrm{H}_{\mathrm{A}}$ levels. The last assumption contradicts to the number of theoretical and experimental works [5,17,22, 23]. An insertion of the intermediate state I between the $\mathrm{P}_{2}^{*} \mathrm{~B}_{\mathrm{A}} \mathrm{H}_{\mathrm{A}}$ and $\mathrm{P}^{+} \mathrm{B}_{\mathrm{A}}^{-} \mathrm{H}_{\mathrm{A}}$ states helps to explain the oscillatory kinetics of the $\mathrm{B}_{\mathrm{A}}^{-}$absorption if to suppose that the I energy is close to the $\mathrm{P}_{2}^{*} \mathrm{~B}_{\mathrm{A}} \mathrm{H}_{\mathrm{A}}$ energy and that the I state has spectral properties of the $\mathrm{B}_{\mathrm{A}}^{-}$.

\subsection{A Possible Nature of the $P_{2}^{*} B_{A} H_{A}$ and $I$ States}

In our model the $\mathrm{P}_{2}^{*} \mathrm{~B}_{\mathrm{A}} \mathrm{H}_{\mathrm{A}}$ state is presumably associated with the $\mathrm{P}^{*}$ stimulated emission band at $940 \mathrm{~nm}$. This band is spectrally and temporally differ from the initially excited $\mathrm{P}^{*}$ emission band at $905 \mathrm{~nm}$ ( $\mathrm{P}_{1}^{*}$ in the model) and is clearly observed in native and mutant RCs at room and low temperatures [3,24]. In the experimental $\Delta A$ spectra the 940-nm emission band forms a long-wavelength tail of the broadband negative signal mainly consisted of the $\mathrm{P}$ absorption band bleaching at $\sim 870 \mathrm{~nm}$. The nature of 940-nm emission band is not well understood. The visible and IR transient spectroscopy indicates that this band may be ascribed to the state with partial charge separation inside the dimer P [24-26]. From the other hand, the hole burning experiments at low temperatures show an absence of the $\mathrm{P}^{*}$ conversion into another state on a time scale much shorter than 1 psec $[27,28]$. The possible charge transfer character of the $\mathrm{P}^{*}$ state may be a result of the electron-spin density shift from $\mathrm{P}_{\mathrm{A}}$ to $\mathrm{P}_{\mathrm{B}}$ in $\mathrm{P}^{*}$ calculated by quantum-mechanical methods [29]. The appearance of the delayed 940-nm feature in the $\mathrm{P}^{*}$ emission spectra may originates from vibrational relaxation or electronic relaxation (or both) or from excitation energy redistribution over vibrational modes in the 
$\mathrm{P}^{*}$ state. It is clear that further studies are need in this question.

As it was mentioned above, the I state was introduced into the model for better fitting of the experimental $B_{A}^{-}$ absorption kinetics at $1020 \mathrm{~nm}$. The population dynamics of the I state is close to the oscillatory component of the experimental $\mathrm{B}_{\mathrm{A}}^{-}$absorption band dynamics. The calculated sum of the I and $\mathrm{P}^{+} \mathrm{B}_{\mathrm{A}}^{-} \mathrm{H}_{\mathrm{A}}$ populations is close to the experimental $\mathrm{B}_{\mathrm{A}}^{-}$kinetics. These results indicate that the I state may contain $\mathrm{B}_{\mathrm{A}}^{-}$or $\mathrm{B}_{\mathrm{A}}{ }^{{ }^{-}}$. One may speculate that $\mathrm{I}$ is the state with charge transfer character between $\mathrm{P}^{*}$ and $\mathrm{B}_{\mathrm{A}}$. To distinguish the $\mathrm{I}$ and $\mathrm{P}^{+} \mathrm{B}_{\mathrm{A}}^{-} \mathrm{H}_{\mathrm{A}}$ states in experiment is very difficult because of their spectral and temporal closeness. No clear experimental evidence of the I state existence is available now.

In our opinion, an advantage of the schemes with the $\mathrm{P}_{2}^{*} \mathrm{~B}_{\mathrm{A}} \mathrm{H}_{\mathrm{A}}$ and $\mathrm{I}$ intermediates consists in the high rates of the reactions in which these states are involved. The $P_{2}^{*}$ $\mathrm{B}_{\mathrm{A}} \mathrm{H}_{\mathrm{A}}$ and I states act as fast mediators between the initially excited $\left(\mathrm{P}_{1}^{*} \mathrm{~B}_{\mathrm{A}} \mathrm{H}_{\mathrm{A}}\right)$ and charge separated states. A stabilization of electron occurs lately in the $\mathrm{P}^{+} \mathrm{H}_{\mathrm{A}}^{-}$state and partially in the $\mathrm{P}^{+} \mathrm{B}_{\mathrm{A}}^{-}$state.

\subsection{A Nature of the Oscillations}

In our model the oscillations in the populations are caused by external modulation of the reaction energetics. A nature of this modulation is beyond the scope of the model. The nuclear motion (not only inside P) can be a possible source of this modulation. Shortly after the excitation of $\mathrm{P}$ by broadband femtosecond pulse the nuclear motion has a coherent character. When the coherence is rapidly damped this motion may continue incoherently due to the nuclear inertia. One can speculate that the incoherent motion may exist a longer timescale than the coherent one, but the latter produces the greater amplitude of the oscillations. The observed oscillations may reflect both the coherent and incoherent motion. The presented model shows that at $\mathrm{t}>150$ fsec the oscillatory features observed in the kinetics of the excited and charge separated states can be explained by incoherent modulation of the reaction energetics.

\section{Acknowledgements}

We are grateful to L.G. Vasilieva and A.Ya. Shkuropatov for preparing RC samples. We acknowledge the partial financial support of the Russian Foundation for Basic Research.

\section{REFERENCES}

[1] W. W. Parson and A. Warshel, "Mechanism of Charge Separation in Purple Bacterial Reaction Centers,” In: C. N. Hunter, F. Daldal, M. C. Thurnauer and J. T. Beatty, Eds.,
The Purple Phototrophic Bacteria, Springer Science + Business Media B.V., Dordreht, 2009, pp. 355-377. http://dx.doi.org/10.1007/978-1-4020-8815-5_19

[2] V. A. Shuvalov, "Primary Light Energy Conversion in Reaction Centers of Photosynthesis," Nauka, Moscow, 2000.

[3] M. H. Vos, M. R. Jones, C. N. Hunter, J. Breton, J.-C. Lambry and J.-L. Martin, "Coherent Dynamics during the Primary Electron-Transfer Reaction in Membrane-Bound Reaction Centers of Rhodobacter sphaeroides," Biochemistry, Vol. 33, 1994, pp. 6750-6757. http://dx.doi.org/10.1021/bi00188a002

[4] A. G. Yakovlev, A. Ya. Shkuropatov and V. A. Shuvalov, "Nuclear Wavepacket Motion Producing a Reversible Charge Separation in Bacterial Reaction Centers," FEBS Letters, Vol. 466, 2000, pp. 209-212. http://dx.doi.org/10.1016/S0014-5793(00)01081-4

[5] V. I. Novoderezhkin, A. G. Yakovlev, R. van Grondelle and V. A. Shuvalov, "Coherent Nuclear and Electronic Dynamics in Primary Charge Separation in Photosynthetic Reaction Centers: A Redfield Theory Approach," The Journal of Physical Chemistry B, Vol. 108, 2004, pp. 7445-7457. http://dx.doi.org/10.1021/jp0373346

[6] D. S. Shchepetov, D. S. Chernavsky, V. V. Gorokhov, N. P. Grishanova, V. Z. Paschenko and A. B. Rubin, "The Nature of Oscillations in the Kinetics of Electron Transfer in the Reaction Center of Purple Bacteria,” Doklady Biochemistry and Biophysics, Vol. 425, 2009, pp. 87-90. http://dx.doi.org/10.1134/S1607672909020082

[7] J. M. Jean and G. R. Fleming, “Competition between Energy and Phase Relaxation in Electronic Curve Crossing Processes,” Journal of Chemical Physics, Vol. 103, 1995, pp. 2092-2101. http://dx.doi.org/10.1063/1.469684

[8] K. Ando and H. Sumi, "Nonequilibrium Oscillatory Electron Transfer in Bacterial Photosynthesis," The Journal of Physical Chemistry B, Vol. 102, 1998, pp. 10991-11000. http://dx.doi.org/10.1021/jp982659l

[9] X. Gu, M. Hayashi, S. Suzuki and S. H. Lin, "Vibrational Coherence and Relaxation Dynamics in the Primary Donor State of the Mutant Reaction Center of Rhodobacter capsulatus: Theoretical Analysis of Pump-Probe Stimulated Emission,” Biochimica et Biophysica Acta, Vol. 1229, 1995, pp. 215-224. http://dx.doi.org/10.1016/0005-2728(94)00197-D

[10] S. H. Lin, M. Hayashi, S. Suzuki, X. Gu, W. Xiao and M. Sugawara, "Theoretical Analyses on Femtosecond TimeResolved Spectra of Initial Electron Transfer of Photosynthetic Reaction Centers at Low Temperatures," Chemical Physics, Vol. 197, 1995, pp. 435-455. http://dx.doi.org/10.1016/0301-0104(95)00186-R

[11] J. A. Leegwater, "Theory of Coherent Oscillations in the Photosynthetic Reaction Center,” The Journal of Physical Chemistry, Vol. 99, 1995, pp. 11605-11611. http://dx.doi.org/10.1021/j100029a044

[12] A. Lucke, C. H. Mak, R. Egger, J. Ankerhold, J. Stockburger and H. Grabert, "Is the Direct Observation of Electronic Coherence in Electron Transfer Reactions Possible?” Journal of Chemical Physics, Vol. 107, 1997, pp. 8397-8408. 
http://dx.doi.org/10.1063/1.475040

[13] W. W. Parson, Z. T. Chu and A. Warshel, "Oscillations of the Energy Gap for the Initial Electron-Transfer Step in Bacterial Reaction Centers,” Photosynthesis Research, Vol. 55, 1998, pp. 147-152. http://dx.doi.org/10.1023/A:1005992121305

[14] D. A. Cherepanov, L. I. Krishtalik and A. Y. Mulkidjanian, "Photosynthetic Electron Transfer Controlled by Protein Relaxation: Analysis by Langevin Stochastic Approach,” Biophysical Journal, Vol. 80, 2001, pp. 10331049. http://dx.doi.org/10.1016/S0006-3495(01)76084-5

[15] H. Sumi and R. A. Marcus, "Dynamical Effects in Electron Transfer Reactions," Journal of Chemical Physics, Vol. 84, No. 9, 1986, pp. 4894-4914. http://dx.doi.org/10.1063/1.449978

[16] A. G. Yakovlev, A. Ya. Shkuropatov and V. A. Shuvalov, "Nuclear Wavepacket Motion between $\mathrm{P}^{*}$ and $\mathrm{P}^{+} \mathrm{B}_{\mathrm{A}}{ }^{-} \mathrm{Po}-$ tential Surfaces with a Subsequent Electron Transfer to $\mathrm{H}_{\mathrm{A}}$ in Bacterial Reaction Centers at $90 \mathrm{~K}$. Electron Transfer Pathway,” Biochemistry, Vol. 41, 2002, pp. 1401914027. http://dx.doi.org/10.1021/bi020250n

[17] A. Warshel and W. W. Parson, "Dynamics of Biochemical and Biophysical Reactions: Insight from Computer Simulations," Quarterly Review of Biophysics, Vol. 34, 2001, pp. 563-679. http://dx.doi.org/10.1017/S0033583501003730

[18] W. W. Parson, Z. T. Chu and A. Warshel, "Electrostatic Control of Charge Separation in Bacterial Photosynthesis,” Biochimica et Biophysica Acta, Vol. 1017, 1990, pp. 251-272. http://dx.doi.org/10.1016/0005-2728(90)90192-7

[19] M. Plato and C. J. Winscom, "A Configuration Interaction (CI) Description of Vectorial Electron Transfer in Bacterial Reaction Centers," In: J. Breton and A. Vermeglio, Eds., The Photosynthetic Bacterial Reaction Center, Plenum, New York, 1988, pp. 421-424. http://dx.doi.org/10.1007/978-1-4899-0815-5_41

[20] Y. Hu and S. Mukamel, "Sequential versus Superexchange Electron Transfer in the Photosynthetic Reaction Center," In: J. Jortner and B. Pullman, Eds., Perspectives in Photosynthesis, Kluwer Acad. Publ., Amsterdam, 1990, pp. 171-184. http://dx.doi.org/10.1007/978-94-009-0489-7_15

[21] A. Warshel, S. Creighton and W. W. Parson, "ElectronTransfer Pathways in the Primary Event of Bacterial Photosynthesis,” The Journal of Physical Chemistry, Vol.
92, 1988, pp. 2696-2701. http://dx.doi.org/10.1021/j100320a057

[22] V. A. Shuvalov and A. G. Yakovlev, "Energy Level of $\mathrm{P}^{+} \mathrm{B}^{-}$with Respect to $\mathrm{P}^{*}$ Found from Recombination Fluorescence Measurements in Pheophytin-Modified Reaction Centers,” Membrane and Cell Biology, Vol. 12, No. 5, 1998, pp. 563-569.

[23] E. Sim and N. Makri, "Path Integral Simulation of Charge Transfer Dynamics in Photosynthetic Reaction Centers,” The Journal of Physical Chemistry B, Vol. 101, 1997, pp. 5446-5458. http://dx.doi.org/10.1021/jp970707g

[24] R. A. Khatypov, A. Yu. Khmelnitskiy, A. M. Khristin, T. Yu. Fufina, L. G. Vasilieva and V. A. Shuvalov, "Primary Charge Separation within P870* in Wild Type and Heterodimer Mutants in Femtosecond Time Domain,” Biochimica et Biophysica Acta, Vol. 1817, 2012, pp. 13921398. http://dx.doi.org/10.1016/j.bbabio.2011.12.007

[25] V. A. Shuvalov and A. G. Yakovlev, "Coupling of Nuclear Wavepacket Motion and Charge Separation in Bacterial Reaction Centers,” FEBS Letters, Vol. 540, 2003, pp. 26-34. http://dx.doi.org/10.1016/S0014-5793(03)00237-0

[26] P. Hamm and W. Zinth, "Ultrafast Initial Reaction in Bacterial Photosynthesis Revealed by Femtosecond Infrared Spectroscopy," The Journal of Physical Chemistry, Vol. 99, 1995, pp. 13537-13544. http://dx.doi.org/10.1021/j100036a034

[27] S. G. Johnson, D. Tang, R. Jankowiak, J. M. Hayes, G. J. Small and D. M. Tiede, "Primary Donor State Mode Structure and Energy Transfer in Bacterial Reaction Centers,” The Journal of Physical Chemistry, Vol. 94, 1990, pp. 5849-5855. http://dx.doi.org/10.1021/j100378a045

[28] P. A. Lyle, S. V. Kolaczkowski and G. J. Small, "Photochemical Hole-Burned Spectra of Protonated and Deuterated Reaction Centers of Rhodobacter sphaeroides," The Journal of Physical Chemistry, Vol. 97, 1993, pp. 69246933. http://dx.doi.org/10.1021/j100128a030

[29] M. Plato, F. Lendzian, W. Lubitz and K. Möbius, “Molecular Orbital Study of Electronic Asymmetry in Primary Donors of Bacterial Reaction Centers,” In: J. Breton and A. Verméglio, Eds., The Photosynthetic Bacterial Reaction Center II: Structure, Spectroscopy, and Dynamics, Plenum, New York, 1992, pp. 109-118. http://dx.doi.org/10.1007/978-1-4615-3050-3_13 